\title{
Increasing The Dynamic Torque Per Ampere Capability Of Induction Machines
}

\author{
Ian T. Wallace, Member, IEEE, Donald W. Novotny, Fellow, IEEE, Robert D. Lorenz, \\ Senior Member, IEEE, and Deepakraj M. Divan, Senior Member, IEEE
}

\begin{abstract}
The objective of this paper is to present a novel means of increasing the dynamic torque per ampere capability of induction machines. The method developed is based on use of an indirect field oriented controller (IFOC) for the induction machine. It is well known that IFOC allows the rotor flux amplitude to be controlled by the $d$-axis component of stator current. It is also well established that the flux-producing component of the stator current may be controlled independent of the torque-producing component of the stator current. The principal constraint, however, is that the amplitude of the peak current (the vector amplitude) is limited by the power electronic switch ratings. This constraint implies that optimal partitioning of the current components should be possible. Previously used methods have optimized steady state efficiency or steady state torque per ampere. This paper identifies a dynamic method which achieves transient torques over $35 \%$ greater than the prior methods. The limitations of the method and its sensitivity to detuning is also examined.
\end{abstract}

\section{INTRODUCTION}

N CONVERTER fed induction machines, the optimal utilization of available converter current is an important issue because of the cost of providing increased converter current capacity. At low speeds, this optimization generally requires operating the machine at maximum torque-per-ampere to achieve high torque output for fast acceleration of the connected load. Field oriented control is well suited to this situation since the independent control of flux and current provides a convenient means of attaining the desired maximum torque-per-ampere. For operation with constant flux, optimal operation requires correct allocation of the available current to the dual tasks of creating the flux and providing torque producing current to interact with the flux. These issues have been addressed in earlier papers $[1,2]$. As will be shown, the proper allocation generally yields higher than rated flux levels and can significantly improve short term torque production. This offers substantial application potential for servo drives, actuators, and in starting loads with high starting torque requirements.

The growing use of induction machines in servo and actuator applications has led to increased interest in load torque profiles in which large, short duration torques are required. In

Paper JF 10-94, approved by the Electric Machines Committee of the IEEE Industry Applications Society for presentation at the 1991 Industry Applications Society Annual Meeting, Dearborn, MI, September 28-October 4. Manuscript released for publication May 11, 1993.

The authors are with the Department of Electrical and Computer Engineering, University of Wisconsin-Madison, 1415 Johnson Drive, Madison, W 53706.

IEEE Log Number 9213441. many cases, these large torque pulses are predictable and/or repeated as, for example, when starting a load with large static friction or in machines driving a repetitive process requiring periods of high torques. In such systems, the allocation of available converter current to flux and torque production becomes a dynamic problem and the proper allocation is time dependent. In an earlier paper [2] concerned with minimizing energy losses during repetitive load cycles, the optimization routine produced a time varying current allocation in which the flux was caused to build up in anticipation of the requirement for a large torque pulse. This indicates that for dynamic torque per ampere optimization the allocation of current must be viewed as a question which fully recognizes the dynamics of the machine. In particular, the lag associated with flux changes can have an important impact on the optimization.

The significance of the lag in the flux response is made clear by the realization that the induction machine can produce torque even if all of the available converter current is applied as torque producing current. This results from the lag in the flux response and the ability of the shorted rotor coils to "trap" and support flux for a period of time following a change in excitation. An important application of this concept is the production of increased starting torque for loads with large static friction. In this case, the start command would initially utilize all of the available converter current to build up the rotor flux to a high value. The full current can then be switched to torque production resulting in increased starting torque during the period in which the initial rotor flux is supported by transient rotor current. The application of this concept of utilizing transient rotor currents to enhance torque production is the topic of this paper.

\section{FIELD ORIENTED INDUCTION MOTOR MODEL}

The model of a current fed induction machine is simplified under field orientation. By aligning the rotor flux $\left(\lambda_{q d r}^{e}\right)$ completely with the $d$-axis, the synchronous frame equations become:

$$
\begin{aligned}
0 & =r_{r} i_{d r}^{e}+p \lambda_{d r}^{e} \\
\lambda_{d r}^{e} & =L_{m} i_{d s}^{e}+L_{r} i_{d r}^{e} \\
\lambda_{q r}^{e} & =L_{m} i_{q s}^{e}+L_{r} i_{q r}^{e}=0 \\
T_{e} & =\frac{3}{2} \frac{P}{2} \frac{L_{m}}{L_{r}} \lambda_{d r}^{e} i_{q s}^{e} \\
s \omega_{e} & =\frac{L_{m}}{\tau_{r}} \frac{i_{q s}^{e}}{\lambda_{d r}^{e}}
\end{aligned}
$$




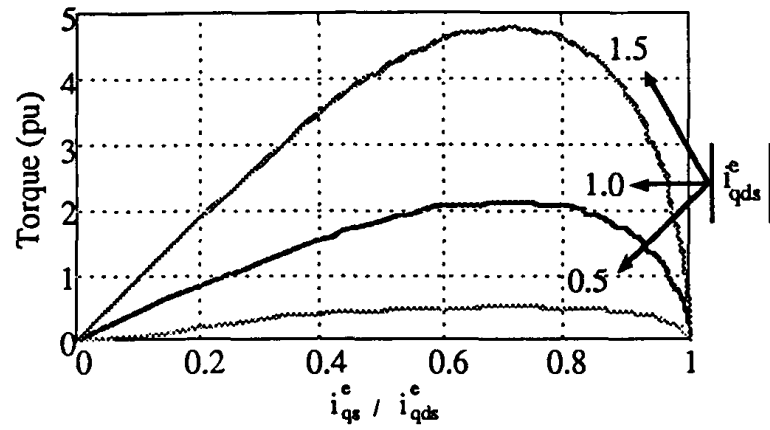

Fig. 1. Field oriented machine steady state torque production as a function of the percentage of torque axis current. (No saturation.)

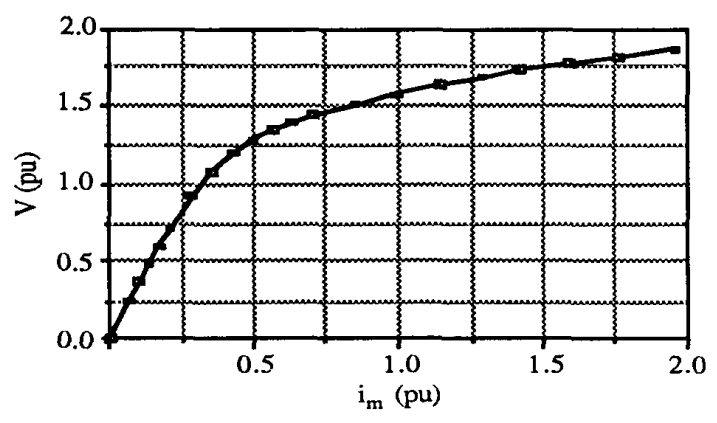

Fig. 2. Saturation curve: rotor flux versus magnetizing current.

\section{MAXIMIZING TORQUE-PER-AMPERE}

\section{A. Steady State Optimization}

Steady state torque production is limited by the motor and inverter current ratings and the need to supply both torque and flux components of current ( $i_{q s}^{e}$ and $i_{d s}^{e}$ respectively). In this case, $i_{d s}^{e}$ is the total magnetizing current which can be seen from (1), (2) and the steady state condition; $p \lambda_{d r}^{e}=0$. Hence the steady state rotor flux equation becomes

$$
\lambda_{d r}^{e}=L_{m} i_{d s}^{e}
$$

To maximize the torque per ampere (4) under a stator current limit, the optimum ratio of $i_{d s}^{e}$ and $i_{q s}^{e}$ must be found, where,

$$
i_{d s^{2}}^{e}+i_{q s^{2}}^{e}=i_{q d s^{2}}^{e}
$$

For the non-saturated case, $\lambda_{d r}^{e}$ is linear with $i_{d s}^{e}$, and the peak torque per ampere occurs when $i_{d s}^{e}=i_{q s}^{e}=0.707 i_{q d s}^{e}$ [1] as is illustrated in Fig 1.

\section{B. Steady State Optimization with Saturation}

The inclusion of saturation in field oriented induction machine modelling requires a knowledge of the motor saturation curve. Fig. 2. shows the measured relationship between the magnetizing current and rotor flux for the motor of Appendix B. In a current fed field oriented induction motor, $i_{d s}^{e}$ is the magnetizing current and is a known variable, thus the saturated

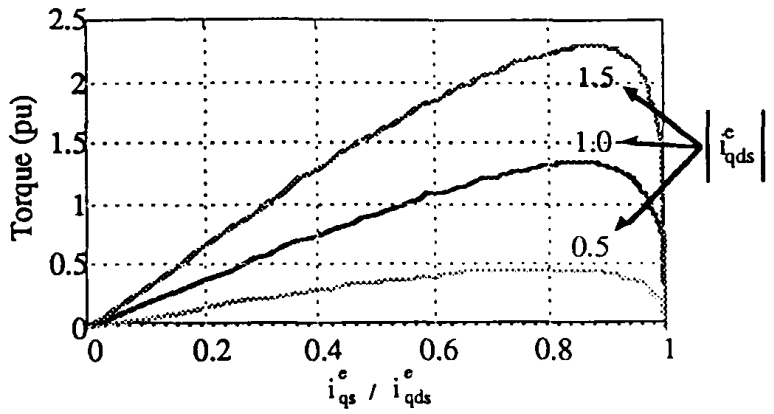

Fig. 3. Field oriented machine steady state torque production as a function of the percentage of torque axis current. (Saturation included.)

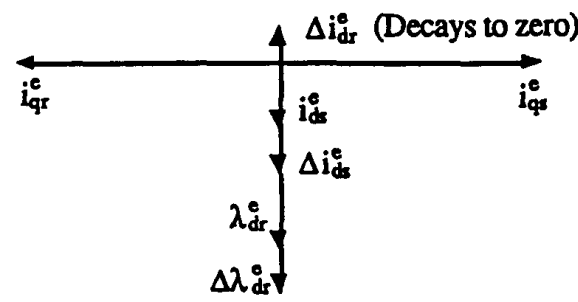

Fig. 4. Response to step changes in flux command.

value of $L_{m}$ can be found from Fig. 2 and (6). The optimum ratio of $i_{d s}^{e}$ and $i_{q s}^{e}$, which maximizes the steady state torque per ampere under a saturated condition is shown in Fig. 3. This shows an increase in $i_{q s}^{e}$ at peak torque over the unsaturated case. This shift can be explained by noting that when saturated, increasing $i_{d s}^{e}$ only produces small flux gains. Thus, peak torque is reached by switching more of $i_{q d s}^{e}$ into the torque axis [1].

\section{TRANSIENT Rotor FLUX AND CURRENT}

Steady state rotor flux is defined by (6), where $i_{d s}^{e}$ is the total magnetizing current $\left(i_{m}\right)$ of the $d$-axis. In the transient case, the secondary winding of the induction motor carries induced currents that combine with $i_{d s}^{e}$ to form $i_{m}$ and produce $\lambda_{d r}^{e}$ (2). It will be shown that a change in the flux command $i_{d s}^{e}$ induces a transient rotor current $i_{d r}^{e}$, which decays with the rotor open circuit time constant and restricts the instantaneous change in rotor flux.

\section{A. Transient Rotor Current}

A current regulated, field oriented controller has direct control of the stator current component $i_{d s}^{e}$. The relationship between the commanded stator and induced rotor current is obtained by eliminating $\lambda_{d r}^{e}$ in (1) and (2),

$$
i_{d r}^{e}=\frac{-L_{m}}{r_{r}+p L_{r}} p i_{d s}^{e} \text { with } \tau_{r}=\frac{L_{r}}{r_{r}}
$$

In the steady state, $p i_{d s}^{e}=0$, which results in $i_{d r}^{e}=0$. Dynamically however, $i_{d r}^{e}$ is proportional to $p i_{d s}^{e}$. That is, in response to a change in $i_{d s}^{e}$, an opposing $i_{d r}^{e}$ is induced to oppose that change. This situation is illustrated in Fig. 4 where an incremental change $\Delta i_{d s}^{e}$ in the current $i_{d s}^{e}$ is shown. 
$i_{\mathrm{de}}^{e}$

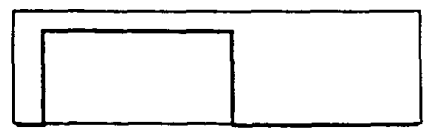

(a)

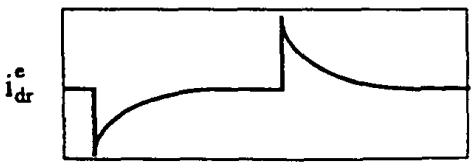

(b)

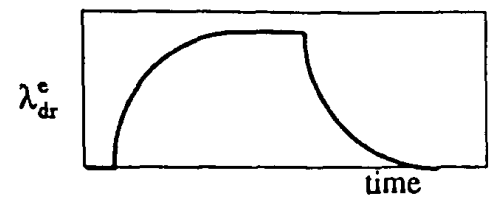

(c)

Fig. 5. Rotor flux and current response to $i_{d s}^{\epsilon}$

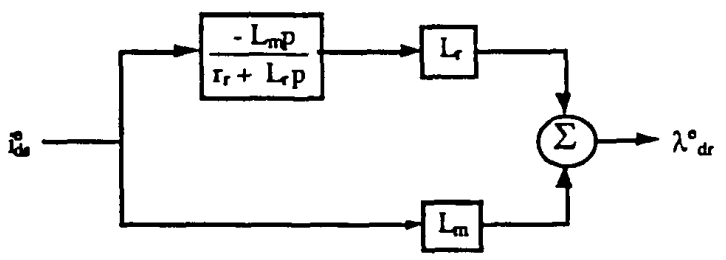

Fig. 6. Transient flux as a function of $i_{d s}^{e}$.

This incremental current results in the induced rotor current $\Delta i_{d r}^{e}$ which initially retards the change in the flux $\lambda_{d r}^{e}$, thus holding it nearly constant. The rate of decay of $\Delta i_{d r}^{e}$ is governed by the rotor open circuit time constant $\tau_{r}$ as shown in (8). The flux changes in response to the change in $i_{d s}^{e}$ only as rapidly as the induced current $\Delta i_{d r}^{e}$ decays toward zero. The lag in the flux response is thus a direct result of the transient rotor current which, according to (8) always opposes the change in flux.

Fig. 5 illustrates the extreme transient case in which $i_{d s}^{e}$ is switched to zero. When $i_{d s}^{e}$ is first turned on, a negative $i_{d r}^{e}$ spike occurs in the rotor, as predicted by (8), which decays to zero with time constant $\tau_{r}$. The reverse is seen when $i_{d s}^{e}$ is forced to zero. Fig. 5 also demonstrates why $i_{d r}^{e}$ decays with the open circuit time constant. A current source effectively open circuits the stator with respect to the rotor. As a result, with no stator current, only the isolated rotor circuit of $L_{r}$ and $r_{r}$ define transient operation.

\section{B. Transient Flux}

Rotor flux is supported by $i_{d s}^{e}$ and $i_{d r}^{e}$ (2). Although the current regulator can change $i_{d s}^{e}$ instantaneously, it has been shown that an $i_{d r}^{e}$ is induced to oppose that change. Consequently, $i_{d r}^{e}$ prevents instantaneous change in the rotor flux. By solving (1) and (2) the dynamic flux equation in terms of $i_{d s}^{e}$ becomes,

$$
\lambda_{d r}^{e}=L_{m} i_{d s}^{e}+\frac{-L_{m} L_{r}}{r_{r}+L_{r} p} p i_{d s}^{e}
$$

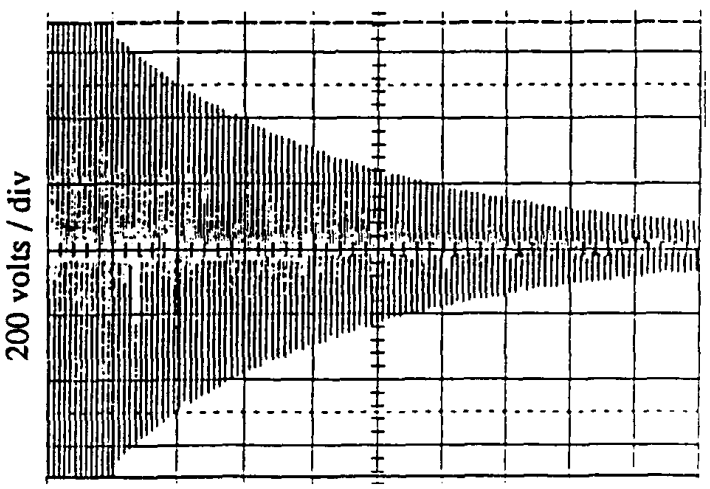

$200 \mathrm{msec} / \mathrm{div}$

Fig. 7. 30-hp, 2-pole induction motor. Motor line voltage after voltage source was disconnected.

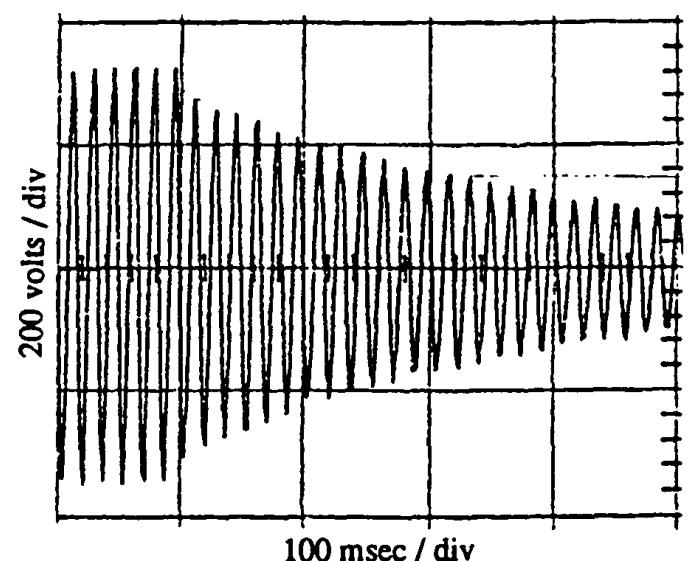

Fig. 8. 10-hp, 4-pole induction motor. Motor line voltage after voltage source was disconnected.

It may be noted that the steady state relationship (6) is obtained by setting $p i_{d s}^{e}=0$.

Fig 6. illustrates the first order lag relationship between $\lambda_{d r}^{e}$ and $p i_{d s}^{\mathrm{e}}$ using a block diagram format. The response to changes in $i_{d s}^{e}$ can also be seen in Fig. 5(c). With the removal of $i_{d s}^{e}$, the induced $i_{d r}^{e}$ effectively traps the flux in the rotor. An important point to note here is that the trapped flux is not supported by inverter input current, but rather is fully dependent on the decaying $i_{d r}^{e}$.

\section{Experimental Flux Decay}

Experiments to demonstrate the trapped rotor flux concept were performed on the motor of Appendix B and a $10 \mathrm{Hp}$ motor, using voltage source excitation. After allowing the motor to reach steady state with no-load, the source was disconnected. Figs. 7 and 8 illustrate that the terminal voltage does not instantly go to zero, but rather decays with the rotor open circuit time constant. Since the stator is an open circuit, the voltage is solely produced by the flux trapped in the rotor. It is also clear from Fig's. $7 \& 8$ that transient flux can exist in an induction motor without the support of stator current. 


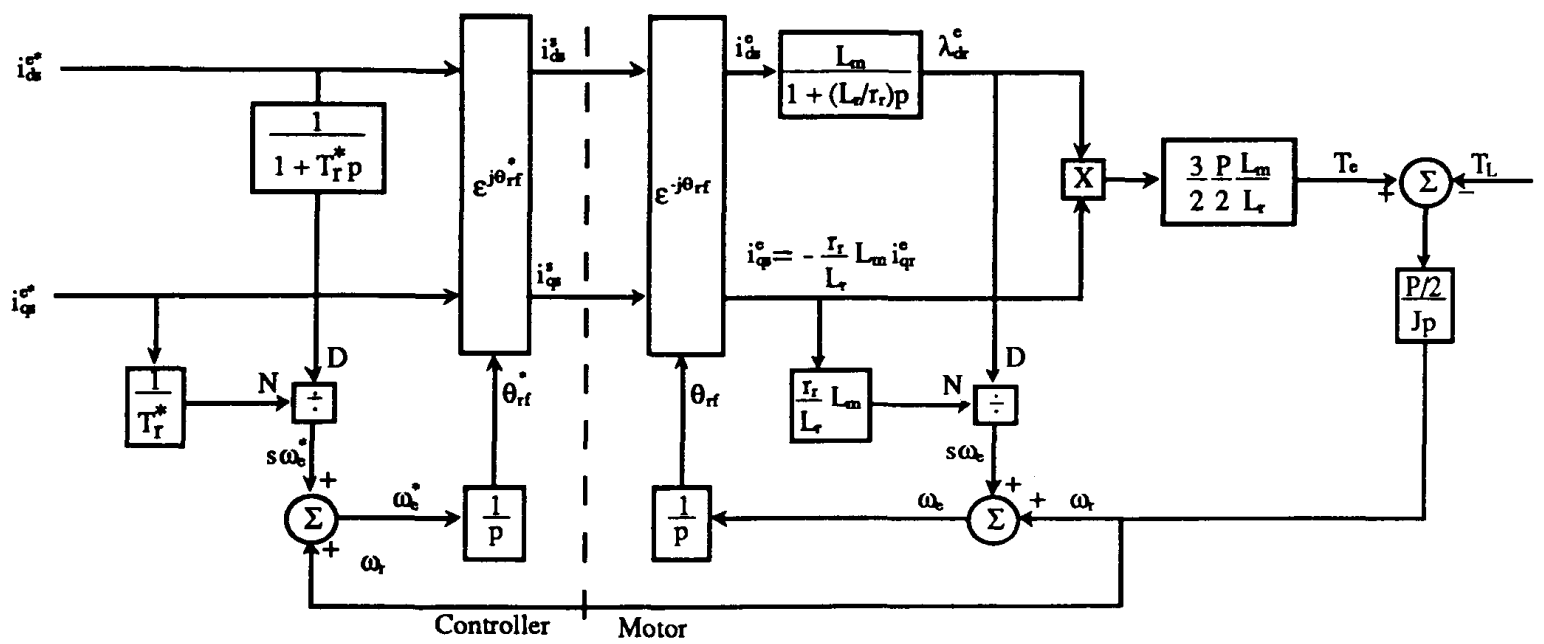

Fig. 9. Simulation of the field orientation controller and saturating induction machine.

The rate of flux decay differs between the two motors. Large motors or motors designed for high efficiency inherently have larger $L_{m}$, resulting in longer decay times. Since $L_{m}$ is also inversely dependent on pole number, the longest time constants are typically found in 2-pole motors.

\section{Optimizing Transient Torque Per Ampere}

Peak steady state torque production, as demonstrated, relies on the correct partitioning of stator current into flux and torque components. However, by utilizing the rotor's inherent ability to trap flux, transient torque per ampere can be increased further.

The maximum current rating of the inverter provides a fixed stator current constraint with which to optimize the transient torque. As in the steady state, the optimum partitioning of $i_{q d s}^{e}$ into $i_{d s}^{e}$ and $i_{q s}^{e}$ must be found. However, in the transient case the trapped flux acts as an added dynamic flux source which does not require stator current support. Hence, unneeded $i_{d s}^{e}$ can be diverted into $i_{q s}^{e}$ to increase torque production.

\section{A. Maximum Transient Torque Per Ampere}

The precise objective function for optimization will define the dynamic partitioning of $i_{q d s}^{e}$. One possible method which maximizes the instantaneous dynamic torque per ampere is as follows:

1. Build up the rotor flux prior to the time peak torque is required.

2. Switch all of the current into the $q$-axis when high torque is required.

The interaction between the decaying flux (Fig. 5c) and large $i_{q s}^{e}$ can produce torque greater than the maximum steady state torque described in section III B.

\section{B. Saturation Concerns}

Typically, the inverter current rating is 1.5 to 2.0 times the motor rated current. Also, under normal operation $i_{d s}^{e}$ is typically of the order of $0.3-0.5$ times rated current. Thus in the method proposed to maximize torque per ampere, the magnetizing current will be 4-5 times normal, causing significant saturation. Concerns with how saturation will effect the performance of the algorithm are discussed and analyzed in the following sections. These include saturation flux level, rate of flux decay and robustness of the field orientation system.

\section{Simulation MODEL}

The main goal of the simulation is to examine the transient torque production, using trapped rotor flux. Fig. 9 is a block diagram of an indirect field oriented induction motor and the controller. The motor model consists of equations (1) to (5). The controller was included to investigate the effects of detuning on the partitioning of stator current, and hence torque production.

\section{A. Field Orientation Controller}

The controller transforms synchronous frame command currents to the stator frame. The transformation angle $\Theta_{r f}^{*}$, the instantaneous position of the rotor flux, is formed by the sum of the rotor speed and $s \omega_{e}^{*}$. The field oriented slip relation (5) relies on programmed values of $L_{r}$ and $r_{r}$ to calculate $s \omega_{e}^{*}$.

\section{B. Field Oriented Induction Motor}

Fig. 9 shows the model of a field oriented induction motor in the synchronous frame, as described by (1) through (5). By applying the field oriented condition, the rotor flux will always be aligned in the $d$-axis, resulting in the $q$-axis flux relationship, $\lambda_{q r}^{e}=0$. The input currents from the inverter are inverse transformed back to the synchronous frame. The transformation angle is computed by a separate slip calculator, using actual motor parameters, $L_{r}$ and $r_{r}$.

The use of two slip calculators makes it possible to detune the controller and study its affects on torque production. The controller's slip calculator is given values of $L_{r}$ and $r_{r}$ which 
will inevitably vary from the actual motor parameters during operation. That is, $r_{r}$ can change due to heating and $L_{r}$ will vary with saturation. When the slip calculator uses incorrect parameters, $s \omega_{e}^{*}$ and $s \omega_{e}$ will differ as will $\Theta_{r f}^{*}$ and $\Theta_{r f}$. In effect, the controller's knowledge of the rotor field position will be incorrect. Fig. 9 illustrates that if the motor and the controller are operating with the same $\tau_{r}$, the actual motor currents will be equal to the commanded currents, yielding ideal field orientation. However, when an error occurs in $\tau_{r}$, the motor currents deviate from the desired currents. An inaccurate value of $\Theta_{r f}^{*}$ will partition $i_{q d s}^{e}$, incorrectly into $i_{q s}^{e}$, and $i_{d s}^{e},(5)$, leading to errors in flux and torque production.

\section{Saturation Modelling}

To model saturation, $L_{m}$ and $\lambda_{d r}^{e}$ became functions of the $d$-axis magnetizing currents, $i_{d s}^{e}$ and $i_{d r}^{e}$. The field oriented motor model of Fig. 9 aligns all the rotor flux with the $d$ axis at all times. Thus, to a first approximation, saturation will occur in the $d$-axis, but not in the $q$-axis. To reflect this in the model the saturated value of $L_{m}$ was only used in $d$-axis calculations $[3,4]$. The effects of detuning and saturation on peak torque production are examined in the next section.

\section{Simulation Results}

Since the proposed torque enhancement technique involves initially utilizing all of the available inverter current to produce flux, the machine will be driven well into saturation. The saturation characteristic of the machine is therefore an important factor in transient torque enhancement just as it was for steady state. To investigate this effect, the machine of Appendix B, subject to an inverter current limit of 1.5 times rated current was simulated. Both ideal field orientation and detuned operation are considered to fully explore the potential of the proposed technique.

\section{A. Ideal Field Orientation}

Fig. 10 shows the dynamic torque result obtained under the assumption of ideal field orientation, i.e. assuming the controller correctly tracks the rotor flux amplitude despite the strong saturation resulting from applying 1.5 times rated current entirely in the flux axis. The peak transient torque under this condition is 3.2 p.u. as shown in the figure. Compared to the steady state optimum under the same current limit of 2.4 p.u., this represents a $35 \%$ increase. The flux decay causes the torque to drop to the steady state peak after about $0.16 \mathrm{sec}$. The flux variation associated with the torque transient in Fig. 10 is illustrated in Fig. 11. With a magnetizing current of 1.5 times rated, the flux reaches 1.8 p.u. Although the unsaturated rotor open circuit time constant of the machine is $0.84 \mathrm{sec}$, the effect of saturation is to reduce the effective time constant at these high flux levels to something closer to $0.3 \mathrm{sec}$. as can be seen from the figure. This reduced time constant results in the rapid decay of the torque and a much shorter period of time during which the enhanced transient torque exceeds the steady state optimal torque.

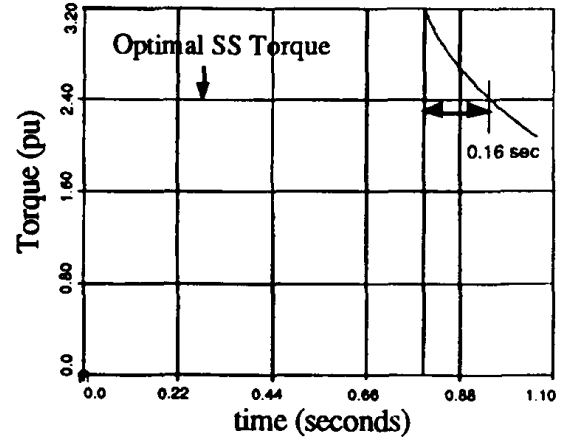

Fig. 10. Enhanced transient torque production for machine of Appendix B.

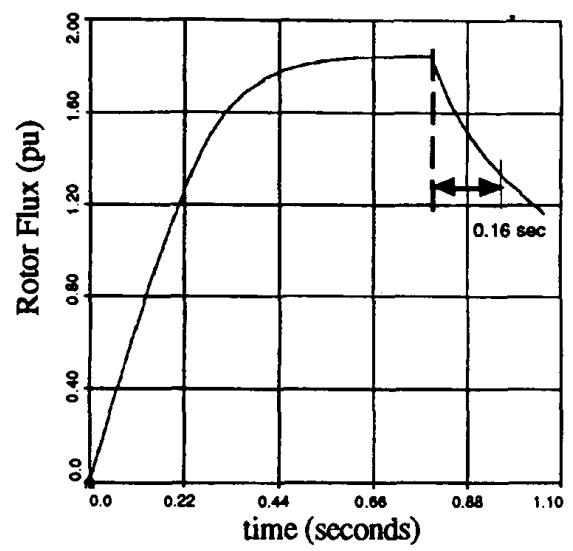

Fig. 11. Flux transient behavior during the enhanced transient torque production for the machine of Appendix B.

\section{B. The Transition to Steady State Peak Torque Operation}

From Fig. 10, it was apparent that after a finite time, the torque had decayed to the level which represented the peak steady state torque capability of the machines. From Fig. 11, it was apparent that after an even shorter time, the flux had already dropped to the level needed for the peak steady state torque capability of the machine and converter. Thus, the transition from the dynamic torque decay trajectory to steady state operation can not occur such that the peak steady state torque and the required steady state flux are simultaneously achieved. Fig. 12 shows two possible transitions.

Two reasonable switching points are the points where

- $\lambda_{d r}^{e}$ is equal to the value for the maximum steady state torque.

- Torque is equal to the value for the maximum steady state torque.

The first case implies that rotor flux will be held to the torque optimizing steady state value but that the stator current will be repartitioned to achieve the required $i_{d s}^{e}$ and thus, $i_{q s}^{e}$ will be decreased with a corresponding instantaneous drop in torque.

The second case implies that the rotor flux will be allowed to decay below the torque optimizing steady state value as long as the torque is at least as great as the maximum steady state 


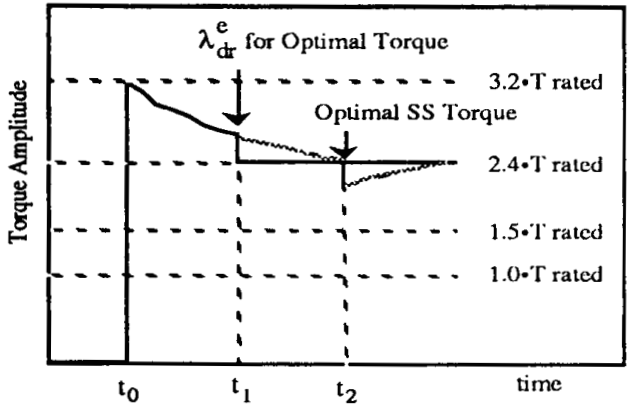

Fig. 12. Torque transition possibilities from the dynamic decay trajectory to the maximum steady state torque.

torque. This approach will also cause an instantaneous drop in torque at the time of the repartitioning of the stator currents to their steady state torque optimizing values. However, this instantaneous drop will be regained after the rotor flux has exponentially increased to its steady state value.

\section{Effect of Non Ideal Field Oriented Control}

The ideal field oriented control illustrated in Figs. 10 and 11 would require that the controller track the nonlinear flux variation associated with the large magnetizing current [5]. While this is feasible using a magnetization curve stored in table form, it is useful to consider the performance obtained with a simple controller using a fixed value of the rotor time constant. Such a controller will be detuned over most of the period of operation and the influence of this detuning is important in considering use of this simpler system.

The results of a simulation of this simple, constant parameter field oriented controller are shown in Figs. 13 and 14. Three values of rotor time constant corresponding to 1) rated flux, 2) the flux for peak steady state torque and 3) the maximum flux obtained with $i_{d s}^{e}=150 \%$ of rated current were simulated. As can be seen from the figures, there is no effect on the initial peak torque and the decay of the torque is not strongly affected except for the shortest time constant case associated with the saturated condition. The flux plots in Fig. 14 indicate a substantial reduction in flux for this case since this short time constant actually results in a demagnetizing flux component of current, also illustrated in Fig. 14. As might be expected, the behavior with the time constant set to the value corresponding to the flux for peak steady state torque yields the best performance. It is interesting to note that the increased torque per ampere attainable is not severely affected by the detuned operation [1], indicating that the technique can be applied in some situations without resorting to complex controllers which compensate for the large flux changes.

\section{Comparison of Acceleration Performance with Optimal Steady State Torque and Dynamic Torque Enhancement}

The added torque achieved with dynamic torque enhancement increases the machine's acceleration rate. Since the dynamic torque $\left(T_{d y n}\right)$ is greater than the optimal steady

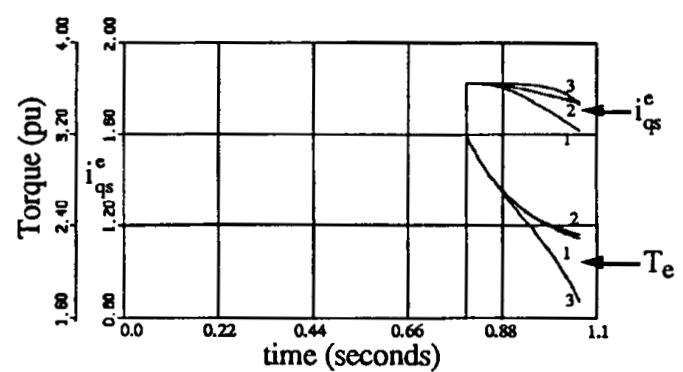

Fig. 13. Torque enhancement with constant values of controller time constant. Time constants correspond to 1) rated flux, 2) flux for peak steady state torque, 3) maximum flux.

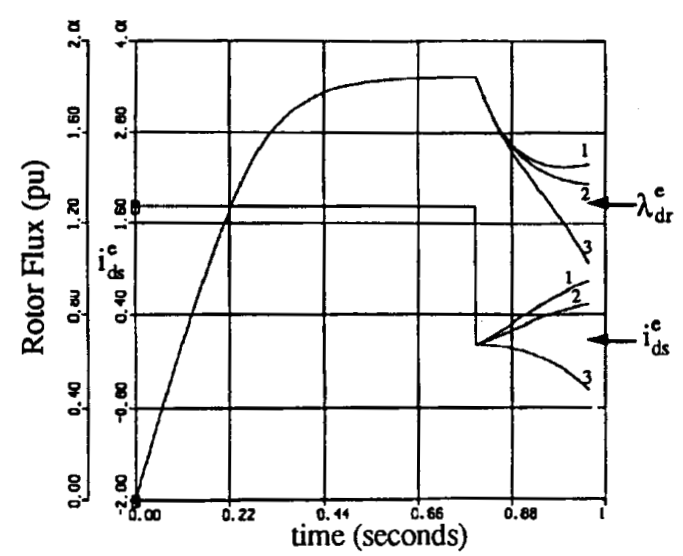

Fig. 14. Flux and d-axis current with constant values of controller time constant. Time constants as in Fig 13.

state torque $\left(T_{s s}\right)$ for a fixed period of time $(\mathrm{t} 1=160 \mathrm{~ms})$, the increased speed of an inertial load can be described as follows.

Speed $(\omega)$ and torque $(T)$ are related by the integral

$$
\omega=\frac{1}{J} \int_{0}^{t} T d \tau
$$

The increase in speed $(\Delta \omega)$ achieved with dynamic torque is

$$
\Delta \omega=\frac{1}{J} \int_{0}^{t 1}\left\{T_{d y n}-T_{s s}\right\} d \tau
$$

The maximum speed increase is limited by the time it takes for the dynamic torque to decay to the optimal steady state level $(t 1=160 \mathrm{~ms}$ in this case).

The effect of the dynamic torque can also be viewed in terms of acceleration times. The increased torque achieved with this dynamic technique will decrease the time it takes to reach a given speed. Fig. 15 compares the times required to accelerate the machine from $0-0.25$ pu speed using both optimal steady state torque and dynamic torque enhancement. The inertia of the system was varied to show how the acceleration times were affected by the addition of a purely inertial load.

The enhanced dynamic torque produced by this machine takes 160 msecs to decay to the optimal steady state level, as shown in Section VII.A. Thus, acceleration to speeds which take less than 160 msecs to reach, benefit most from the 


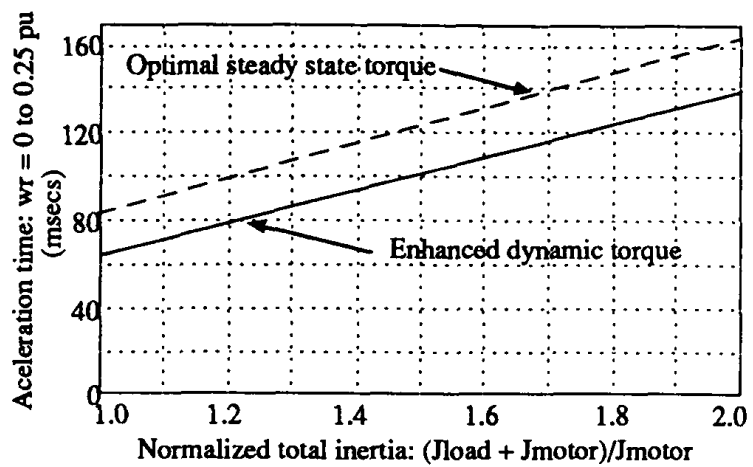

Fig. 15. Comparison of time required to accelerate from zero speed to 0.25 times rated speed, for a range of load inertias.

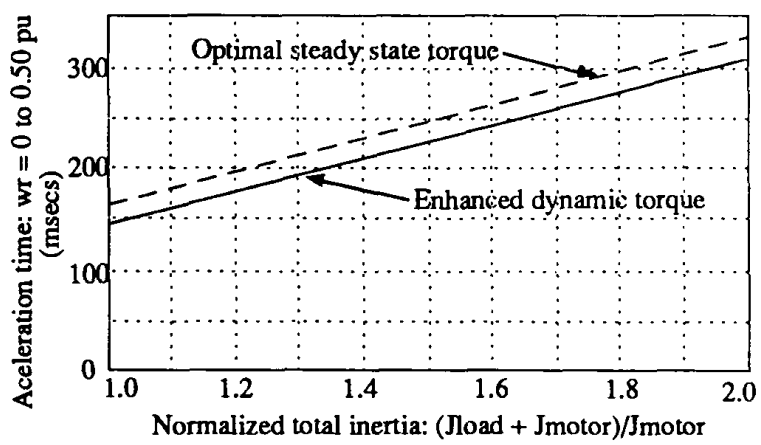

Fig. 16. Comparison of time required to accelerate from zero speed to 0.5 times rated speed, for a range of load inertias.

dynamic technique. This is visible in Fig. 15; as the inertial load is increased, the difference between the acceleration time also increases. Fig. 16 plots the acceleration times required to reach $0.5 \mathrm{pu}$ speed. Its shows that after the 160 msecs of increased dynamic torque, the difference between acceleration times does not increase but rather, stays constant. This occurs since after 160 msecs the machine would be operated at optimal steady state torque.

\section{APPLICATION AND OPTIMIZATION ISSUES}

The example used in the paper is only one of a number of possible ways in which the rotor induced magnetizing current can be used to enhance performance. It is expected that machine and drive application engineers will use a variety of objective functions to optimize the desired torque-time characteristics of a machine design or of the drive control routines. In general, each case must be optimized to its specific constraints. However, some objective functions will undoubtedly prove very useful. For example, an induction servo designer handling short, 10 to $50 \mathrm{msec}$. bursts of acceleration torque commands may choose to optimize the machine and converter for the peak torque time integral or for the peak torque/average torque ratio over the burst interval. A servo drive application engineer may need to balance the short term peak energy consumption with the continuous cycle losses in order to properly include this peak torque enhancement in his drive sizing analysis. [2]

Because of the relatively low sensitivity to detuning which was observed in this work, it is expected that determination of optimal current partitioning during operation could become a routine analysis. Optimal machine design and optimal control design could also lead to substantial opportunities for machine designers and for drive system engineers. Questions related to best saturation characteristics, percent magnetizing current and rotor time constant effects on the desired performance enhancement are still being investigated to provide the correct fundamental design basis.

Since the technique does involve increasing the flux level it is restricted to operation at lower speeds where the inverter voltage is high enough to maintain good current control. In this respect it is also important to note that the power associated with the increased torque comes from the power converter and is not related to the magnetic energy stored in the machine. The increased flux raises the motor voltage and is the mechanism for delivering the increased power output.

\section{CONCLUSION}

The concept of utilizing induced rotor magnetizing current to increase the dynamic torque per ampere of a field oriented induction machine has been outlined and demonstrated through simulation. The nonlinear flux decay of known machines has been verified experimentally. The motor chosen for analysis and testing would yield a $35 \%$ increase in dynamic torque over the best possible steady state torque. Such dynamic peak torque capability is useful in situations such as peak acceleration or load disturbance rejection where the flux can be built up to a large value before the peak torque is required. It should be emphasized that this increase in torque is attained strictly through optimal dynamic allocation of current and does not require any modification of the power converter or motor. Preliminary analysis also indicates that the technique is robust with regard to field orientation control parameters and in some situations a simple constant parameter controller may be sufficient to attain significant torque enhancement.

The impact of this enhancement technique depends substantially on the converter rating constraints for a specific application. For aerospace actuator applications, the weight penalty may be sufficient to justify the modest additional control complexity. For electric vehicle applications the cost and vehicle weight penalties with the demands for acceleration performance may also be sufficient to warrant its use. The application to starting loads with large static friction is the most obvious and simplest case and should provide a significant improvement with only a modest increase in control complexity.

\section{APPENDIX A}

Parameter Definitions

$i_{q d s}^{e} \quad$ stator current vector in excitation frame

$i_{d s}^{e}, i_{q s}^{e} \quad d$ and $q$ axes components of $i_{q d s}^{e}$, respectively

$i_{q d r}^{\mathrm{e}} \quad$ rotor current vector in excitation frame

$i_{d r}^{e}, i_{q r}^{e} \quad d$ and $q$ axes components of $i_{q d r}^{e}$, respectively 
$\lambda_{q d r}^{e} \quad$ rotor flux vector in excitation frame

$\lambda_{d r}^{e}, \lambda_{q r}^{e} d$ and $q$ axes components of $\lambda_{q d r}^{e}$, respectively

$L_{m} \quad$ mutual inductance

$L_{r} \quad$ rotor self inductance

$r_{r} \quad$ rotor resistance

$\tau_{r} \quad$ rotor time constant

$\omega_{e} \quad$ excitation frequency

$\omega_{r} \quad$ rotor frequency

$s \omega_{c} \quad$ slip frequency

$\theta_{r f} \quad$ angle (position) of rotor flux vector, $\lambda_{q d r}$

$p \quad$ differential operator

$P \quad$ number of pole pairs

$T_{e} \quad$ electromagnetic torque

$T_{L} \quad$ load torque

\section{APPENDIX B}

\section{Machine Parameters}

$\begin{array}{ll}30 \mathrm{Hp}, 3 \emptyset & L_{m}=3.03 \text { p.u. } \\ 230 / 460 \mathrm{~V} & L_{r}=3.09 \text { p.u. } \\ 68.4 / 34.2 \mathrm{~A} & L_{\mathrm{s}}=3.11 \text { p.u. } \\ \text { 2-poles } & r_{r}=0.0097 \text { p.u. } \\ & r_{s}=0.0176 \text { p.u. }\end{array}$

\section{REFERENCES}

[1] R. D. Lorenz and D. W. Novotny, "Saturation Effects in Field Oriented Induction Machines," IEEE Trans. on Ind. Appl.. Vol 26. No. 2. March/April, 1990, pp. 262-268.

[2] R. D. Lorenz and S. M. Yang, "Efficiency Optimized Flux Trajectories for Closed Cycle Operation of Field Oriented Induction Machin Drives " Conf Record of IEEE IAS Annual Meeting, 1988, pp. 457-462.

[3] J. A. Melkebeek; "Magnetising-Field Saturation and Dynamic Behavior of Induction Machines, Part 1: Improved Calculation Method for Induction Machine Dynamics," IEE Proc., Vol 130. Pt. B No. 1, 1983 pp. $1-9$.

[4] Yi-Kang He and T. A. Lipo, "Computer Simulation of an Induction Machine with Spatially Dependent Saturation," IEEE Trans. on Power App. and Systems, Vol. PAS-103, No. 4, April 1984, pp. 707-714.

[5] E. Levi and V. Vučković, "Field-Oriented Control of Induction Machines in the Presence of Magnetic Saturation," Electric Machines and Power Systems, Vol. 16, No. 2, pp. 133-147, 1989

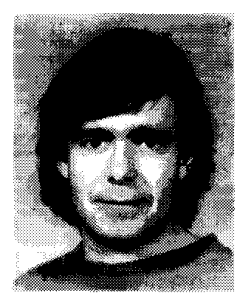

Ian T. Wallace (S91-M92) received the B.S. degree in electrical engineering from Pennsylvania State University in 1989. He earned the M.S.E.E. degree from the University of Wisconsin-Madison in 1992 and is currently pursuing the Ph.D. degree at the same institution.

Prior to entering graduate school he was $\mathrm{cm}$ ployed as an electrical and manufacturing engineer by Ford Motor Company's Electronics Division. His research interests include power converters and the control of ac machines.

Donald W. Novotny (M'62)-SM'77-F'87), for a photograph and biography, see this issue, p. 100 .

Robert D. Lorenz ( $\mathrm{S}^{`} 83-\mathrm{M}^{`} 84-\mathrm{SM}^{`} 92$ ), for a biography see this issue, p. 110

Deepakraj M. Divan ( $S M^{\prime} 91$ ) received the $B$. Tech degree in electrical engineering from the Indian Institute of Technology, Kanpur. India, in 1975. $\mathrm{He}$ also received the M.Sc. and Ph.D. degrees in electrical engineering from the University of Calgary, Calgary, Alberta, Canada.

He worked for two years as a Development Engineer with Philips India. Ltd. After linishing his Master"s program in 1979, he started his own concern in Pune. India. providing product development and manufacturing services in the power electronics and instrumentation areas. In 1983, he joined the Department of Electrical Engineering at the University of Alberta as an Assistant Professor. Since 1985, he has been with the Department of Electrical and Computer Engineering at the University of Wisconsin-Madison, where he is presently a Professor. He is also an Associate Director of the Wisconsin Electric Machines and Power Electronics Consortium (WEMPEC), which is a group of approximately 45 industrial sponsors supporting research in the area of power electronics and machines. His primary areas of interest are in power electronic converter circuits and control techniques. He has over 40 papers in the area as well as many patents. He is a consultant for various organizations including the Electric Power Research Institute, Oakridge National Laboratory, and is working with several industries.

Dr. Divan was a recipient of the Killam Scholarship during the Ph.D program and has also won various prize papers including the IEEE-IAS Best Paper Award for 1988-1989, prize papers for the Industrial Drives Committee in 1989 and 1991, the Industrial Power Converter Committee in 1983,1989. and 1991, and the Power Semiconductor Commince in 1990. He has been the Program Chairman for the 1988 and 1989 Industrial Power Converter Committe of the IEEE-IAS, Transactions Review Chair for the Committee in 1990) and 1991. and is presently Vice Chairman of the Committee. He was Technical Program Chairman for PESC ${ }^{\circ} 91$ and a Treasurer for PESC 89 . He was also Chairman of the Education Committee in the IEEE Power Electronics Society during 1990 and 1991 and is presently an elected Member at Large in the Society"s Administrative Committee. $\mathrm{He}$ is a member of the $\mathrm{R}$ and $\mathrm{D}$ Committee of the Power Sources Manufacaturers Association and has been a member of the National Committee on Power Electronics. 